\title{
Discriminating Depression, Physical and Social Anhedonia by Neurotransmitter Related Challenge Tests
}

\author{
Petra Netter ${ }^{1,2 *}$, Juergen Hennig1,2 \\ ${ }^{1}$ Department of Psychology, University of Giessen, Giessen, Germany \\ ${ }^{2}$ Institute of Psychobiology and Behavioural Medicine, Giessen, Germany \\ Email: petra.netter@psychol.uni-giessen.de
}

Received 2 December 2015; accepted 8 March 2016; published 11 March 2016

Copyright (C) 2016 by authors and Scientific Research Publishing Inc.

This work is licensed under the Creative Commons Attribution International License (CC BY). http://creativecommons.org/licenses/by/4.0/

(c) (7) Open Access

\section{Abstract}

The aim of this study was to investigate, if anhedonia, a salient component of depression, shows similar response patterns to neurotransmitter challenge tests as depression, and if the two questionnaire based components Physical (PA) and Social (SA) Anhedonia can be discriminated by differences in drug related size and time of cortisol responses elicited by the specific serotonin (5HT) and noradrenaline (NA) reuptake inhibitors citalopram and reboxetine and prolactin responses to the dopamine (DA) agonist bromocriptine orally applied to 36 male volunteers in a double blind balanced cross-over design. Analyses of variance applied to placebo corrected hormone responses revealed that low and late DA responses were characteristics of global Depression and of Physical Anhedonia, and that low DA responses were associated with high NA responses in PA, and with low 5-HT responses in SA. These patterns were explained by differences in transmitter production and receptor sensitivities and proved to be suitable to discriminate PA from SA and from global depression by analysing neurochemical response patterns rather than single means of variables.

\section{Keywords}

Depression, Anhedonia, Challenge Tests, Serotonin, Dopamine, Noradrenaline

\section{Introduction}

In recent years, analysis of networks and patterns has become a more promising approach to diagnosing psy-

\footnotetext{
${ }^{*}$ Corresponding author.
} 
chopathological symptoms and states than relying on single biological markers. This also refers to identifying individual differences in Psychology and is not restricted to neurophysiological biomarkers but can also be applied to biochemical characterisation of individuals. In Psychiatry, the so called neurotransmitter challenge tests have frequently been applied for detecting disturbances in synthesis or release of the neurotransmitters noradrenalin, serotonin or dopamine as underlying biological mediators of psychiatric disturbances (e.g. review by Hasler et al., 2004). This is achieved by applying drugs that inhibit or stimulate the activity of these transmitters in the brain which leads to changes in release of hormones from the pituitary and adrenal cortex that can be measured in plasma and may serve as indicators of respective neurotransmitter abnormalities (see van de Kar, 1998).

Particularly in affective disorders abnormalities in response to neurotransmitter challenge tests have been investigated (e.g. review by Power \& Cowen, 1992; Yatham \& Steiner, 1993 for the serotonergic systems or review by Coupland et al., 1992 for the noradrenergic system, and by Insel \& Sievers, 1981 for the dopaminergic system). Depressed patients, for instance, have been reported to show blunted hormone responses to the 5-hydroxy-tryptamine (5-HT) releaser d-fenfluramine (Cleare et al., 1996), the 5-HT-reuptake inhibitors citalopram (Mattos et al., 2006), or clomipramin (Anderson et al., 1992), as well as increased hormone responses to stimulation of the noradrenertgic system (NA), e.g., by the alpha2 receptor agonist clonidine (Charney et al., 1982; Lesch et al., 1988) or the noradrenaline reuptake inhibitor reboxetine (Schüle et al., 2004). Depressed patients also have been shown to exhibit low dopaminergic activity (Boadie et al., 2007) indicated e.g. by abnormal responses to dopamine agonists like apomorphine (Pitchot et al., 1992; Dailly et al., 2004; Stein, 2008).

Several psychiatric disturbances, like anxiety or impulse control disorders and depression, have been shown to represent the end of a continuum from the normal range of personality characteristics into psychopathology (Eysenck, 1967; Pukrop et al., 2000; Livesley, 1998; Widiger, 2011). This can not only be demonstrated by an overlap between questionnaire scores on psychopathological symptoms observed in healthy samples and in clinical groups, but also has been demonstrated for neurotransmitter challenge tests applied to characterize respective personality traits (e.g. Bond, 2001; Hennig \& Netter, 2005). Healthy volunteers scoring high on depression related traits, for example, could be shown to resemble depressed patients in their responses to serotonergic stimulation by citalopram (e.g. Lotrich et al., 2005), or by clomipramine (Ruegg et al., 1997; Gerra et al., 2000). Similarly, increased cortisol responses to the noradrenaline reuptale inhibitor reboxetine in depressive healthy persons mirrored the effect of a noradrenergic challenge observed in depressed patients (Hennig et al., 2000), and a challenge by the dopamine D2 receptor agonist bromocriptine in healthy persons confirmed decreased dopaminergic activity observed in patients (Netter, 2006).

But these findings cannot always be replicated in different samples and at different time points. Inconsistencies in relating psychiatric symptoms or personality dimensions to neurotransmitter responses may partly derive from focusing merely on a single transmitter system at a time in the same population or sample instead of investigating constellations of transmitter responsiveness. Since neurotransmitter systems considerably influence each other and imbalance between systems has often been claimed to underlie psychiatric disturbances (Riederer \& Birkmayer, 1980), it is essential to assess the sensitivities of different transmitter systems and their interactions in the same individuals as to identify neurochemical specificity of depression subtypes.

One of the salient symptoms of depression is anhedonia (Stein, 2008; Lemke, et al., 1999), which is characterized by loss of interests and of enjoyment of previous activities (Snaith, 1993; Nakonezny et al., 2010; Gutkovich et al., 2011). It can also be observed in animals showing reduced motor activity and consumption of food after exposure to chronic mild stress (Willner, 1995, 2005) and could be shown to be associated with low dopaminergic activity in the mesolimbic system (Papp et al., 1994). So one of the hypotheses would be that a deficit of dopaminergic activity should become evident in anhedonia assessed in healthy humans as well.

According to Chapman et al. (1976) two sub-dimensions of anhedonia have been identified by factor analysis which form the subscales of their Anhedonia Scale: Physical Anhedonia (PA) means not being susceptible to rewards by any kind of sensory stimuli (visual, acoustic, tactile, gustatory, movement), Social Anhedonia (SA) means being rather by oneself than with others and not taking interest in social activities: Although both aspects refer to loss of the ability to enjoy and to withdrawal from previously rewarding activities, they might represent different aspects of depression. So it is worthwhile to ask, if the two factors of anhedonia can be discriminated by their patterns of transmitter responsiveness, and if they are associated with patterns different from those linked to the larger concept of depression

Besides the size of hormone responses to transmitter related challenge tests, the time the hormone takes to respond to pharmacological stimulation has been shown to be a relevant variable for discriminating different types of receptor sensitivities (Depue et al., 1994; Netter et al., 2004; Netter, 2006). 
So the major questions to be investigated by the present study are:

1) Can Physical and Social Anhedonia be discriminated by differences in response patterns to pharmacological challenges by dopaminergic, serotonergic and noradrenergic substances and are these patterns different from responses characteristic of global depression?

2) Can time and size of hormone responses contribute differently to the discrimination between depression, Physical and Social Anhedonia?

\section{Method}

\subsection{Subjects}

A sample of 36 male students (18 - 35 years) selected according to a health questionnaire on a separate day participated in the experiment. Exclusion criteria were endocrinological, allergic, or cardiovascular diseases, previous or present neurological or psychiatric symptoms or psychotherapy, any drugs used as medication for the diseases mentioned above and body mass index $>26$. The subjects signed informed consent and were instructed about data protection and told that they could leave the experiment any time. They were also requested to report any kind of side-effects to the experimenter. After completion of all our sessions (see below) they were rewarded by 200 Euro.

The study was approved by the Ethics Committee of the German Psychological Association.

\subsection{Design and Medication}

Participants were subjected to a double blind fourfold balanced cross-over design based on oral intake of the serotonin (5-HT) reuptake inhibitor citalopram (Cit., $30 \mathrm{mg}$ ), the noradrenaline (NA) reuptake inhibitor reboxetine (Reb., $2 \mathrm{mg}$ ), the dopamine (DA) D2-agonist bromocriptine (Bromo., $1.25 \mathrm{mg}$ ) and placebo (Plac) at one week intervals performed at the same time of day.

\subsection{Procedure and Questionnaires}

On experimental days blood sampling for determination of hormones was achieved from an indwelling cannula which was inserted into the antecubital vein of the non-dominant arm at 12.15 p.m., followed by a standard meal of $\approx 700 \mathrm{kcal}$. Then participants filled in the Anhedonia Scale by Chapman et al. (1976) (see above: 84 items based on a dichotomous yes/no score; PA: 48 items, reliability: Cronbach's alpha: 0.84; SA: 40 items, Cronbachs alpha: 0.78) and the Depression Scale by von Zerssen \& Koeller (1976) (16 items scored by a four point Likert scale and related to symptoms of clinical depression like negative effect, lack of drive and psychosomatic symptoms). After administration of the drug at 3.00 p.m. baseline blood sampling took place and was continued at $1 / 2$ hour intervals until 7 p.m. (10 samples). Blood was drawn through a dark rubber tube leading through the wall to an adjacent room so that participants were unaware of the time of blood sampling.

\subsection{Measurement of Hormones}

Since most transmitter related substances elicit cortisol as well as growth hormone and prolactin responses (Hennig \& Netter, 2005), these three hormones were measured in the present experiment as responses to each of the three substances and placebo. However, the hormones cortisol as an indicator of the response to the serotonergic and the noradrenergic drug and prolactin as an indicator of the response to bromocriptine emerged to be the most reliable and sensitive indicators for responses to the specific challenge substances used, while growth homone responses to citalopram, reboxetine and bromocriptine seemed to be liable to produce artifacts and prolactin response was not sensitive enough to citalopram and reboxetine. Blood samples were drawn in serum tubes (Sarstedt, Nuembrecht, Germany) and were kept at room temperature for 20 minutes prior to centrifugation (2000 g). Immediately afterwards, $1 \mathrm{ml}$ of serum was removed and stored at -30 degrees $\mathrm{C}$ until assayed. For cortisol and prolactin, serum samples were thawed immediately prior to measurement which was performed with commercial enzyme immunoassays (DRG, Marburg, Germany). All samples were run in duplicate. Assay protocols were applied to a fully automated system (Labotech, Biochem, Freiburg, Germany) yielding highly precise measurements for cortisol and prolactin with intra- and inter-assay coefficients of variance lower than $5 \%$ and $8 \%$, respectively. 


\subsection{Derivation of Variables}

In order to quantify interactions between time and size of hormone responses and between two different transmitter responses, dichotomised size and time of hormone responses served as independent variables and the questionnaire scores as dependent variables. For obtaining size and time of responses, the following steps were taken: 1) Cortisol raw scores obtained with placebo at each time point were subtracted from respective values obtained with citalopram and reboxetine respectively. Similarly, prolactin raw scores obtained with placebo were subtracted from those obtained with bromocriptine (here large negative values would indicate high responses). 2) For comparison of cortisol and prolactin responses, both sets of values were transformed into zscores for each time point based on means of the respective hormone responses across all time points of the total sample. 3) In these z-transformed curves representing differences between drug and placebo responses of hormones across 10 time points the baseline value was subtracted from the highest peak (lowest value with prolactin). 4) This measure was dichotomised yielding size of response with two groups scoring below and above 0.60 standard deviations of the total group respectively. So scores $\leq 0.60$ standard deviations (SD) were classified as low, those $>0.60 \mathrm{SD}$ as high responders. Time of response was defined as the time point of peak cortisol response to reboxetine and to citalopram, and time of initial decrease of prolactin after intake of bromocriptine. Early responders were defined as responding $90 \mathrm{~min}$ or less after drug intake and late responders as those responding later than 90 minutes after drug intake (Identical cut off points close to the median were possible due to very similar kinetics ( $\mathrm{t}$ max and half lives) of the three drugs).

\subsection{Statistical Evaluation}

Two-factorial analyses of covariance were performed 1) for size of responses between pairs of dichotomized drug responses (Cit $\times$ Reb, Cit $\times$ Bromo, Reb $\times$ Bromo) as independent variables and the 3 questionnaire scores PA, SA and Depression as dependent variables; 2) for time and size of responses (2 levels each) within each of the three transmitter related drug condition. In both cases the covariates were: body mass index and number of cigarettes smoked, because smoking had not been used as an exclusion criterion and is liable to be associated with hormone responses as well as with the questionnaire scores.

This strategy for evaluation was chosen, because hormone responses were partly not normally distributed and furthermore, the sample size was too small as to allow for multiple regressions with 6 independent variables (time and size of each drug related hormone response). The significance level was set at alpha $=0.05$, but tendencies of values $p>0.05$ and $p<0.10$ will also be reported.

\section{Results}

Results will be presented within each of the dependent variables first with respect to constellations of sizes of responses to pairs of drugs and then with respect to interactions of time and size of each single drug response.

\subsection{Global Depression}

Global depression scores were only marginally associated with the size of responses as can be seen from Figure 1 showing the interaction between size of responses to citalopram and reboxetine $\left(\mathrm{F}_{1 ; 33}=3.71 ; p=0.096\right)$. The combination of high noradrenergic and high serotonergic responses was associated with highest depression scores. No significant results or tendencies were obtained for the combined effects of citalopram and bromocriptine or reboxetin and brocriptine.

For the interaction between time and size of responses results only showed a significant effect for the dopaminergic drug (Figure 2): low and late prolactin responses to bromocriptine were particularly characteristic of persons scoring high on depression (interaction: $\left(\mathrm{F}_{1 ; 33}=5.24 ; p=0.015\right)$.

\subsection{Physical Anhedonia (PA)}

Evaluation of reboxetine in combination with bromocriptine responses revealed that besides the main effects for each drug $\left(\mathrm{F}_{1 ; 33}=4.96 ; p=0.027\right.$ for reboxetine and $\mathrm{F}_{1 ; 33}=7.56 ; p=0.009$ for bromocriptine $)$ a significant interaction $\left(\mathrm{F}_{1 ; 33}=5.22 ; p=0.016\right)$ indicated that high PA was particularly pronounced in participants who showed high responses to reboxetine and low responses to bromocriptine, as shown in Figure 3. There were no 


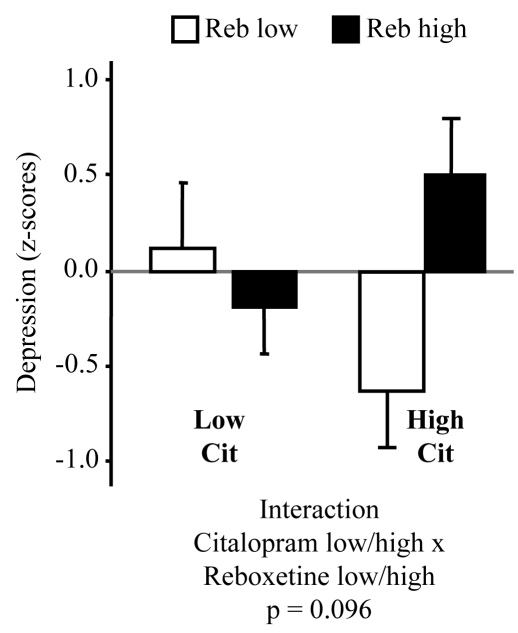

Figure 1. Depression scores according to high and low responses to citalopram and and reboxetine.

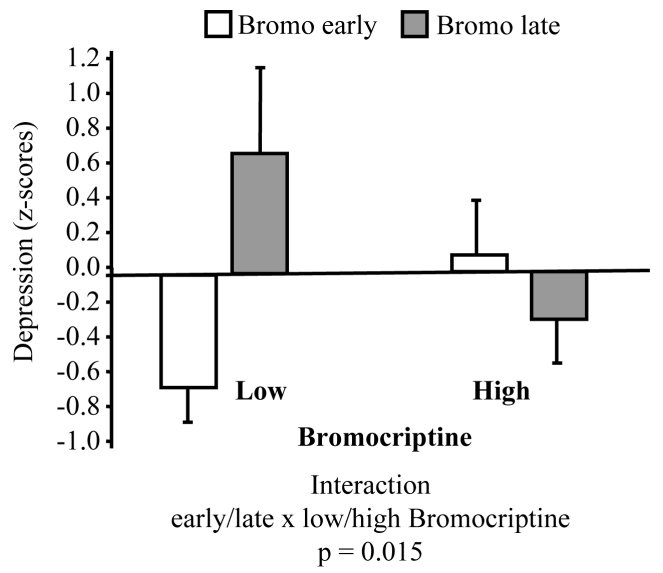

Figure 2. Depression scores according to size and time of responses to bromocriptine.

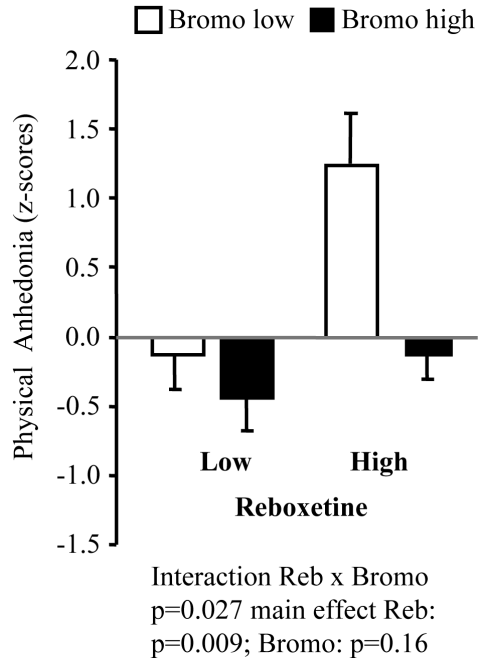

Figure 3. Physical Anhedonia according to sizes of reboxetine and bromocriptine responses. 
effects or interactions observed for responses to the serotonergic drug citalopram.

Furthermore, low responses to bromocriptine were again associated with late onset of decrease of prolactin for participants high on PA as shown by the interaction of time and size of responses to bromocriptine $\left(\mathrm{F}_{1,33}=\right.$ 4.83; $p=0.026$ ) in Figure 4. The cortisol responses to reboxetine of high PA participants, however, rather tended to occur within the first 90 minutes as indicated by a marginal difference between early and late responders, but without showing an interaction with size of cortisol responses (mean \pm (SEM) in z-scores of PA: early responders: $+0.233(0.321)$, late responders: $\left.-0.384(0.214), \mathrm{F}_{1 ; 33}=3.86 ; p=0.093\right)$. No time effects were observed for citalopram.

\subsection{Social Anhedonia (SA)}

Transmitter responses observed for Social Anhedonia differed from both Depression and PA: As shown in Figure 5: high SA was particularly characterized by a low citalopram response (main effect $\mathrm{F}_{1 ; 33}=7.43 ; p=0.011$ ) which became most pronounced when combined with a low response to bromocriptine (interaction $\mathrm{F}_{1 ; 33}=4.68$; $p=0.030$ ). No side effects were observed for reboxetine, and time effects did not become significant for any of the three drugs.

\subsection{In Summary}

The following significant relationships have been obtained for the three questionnaire scales regarding time and size of responses (Figure 6).

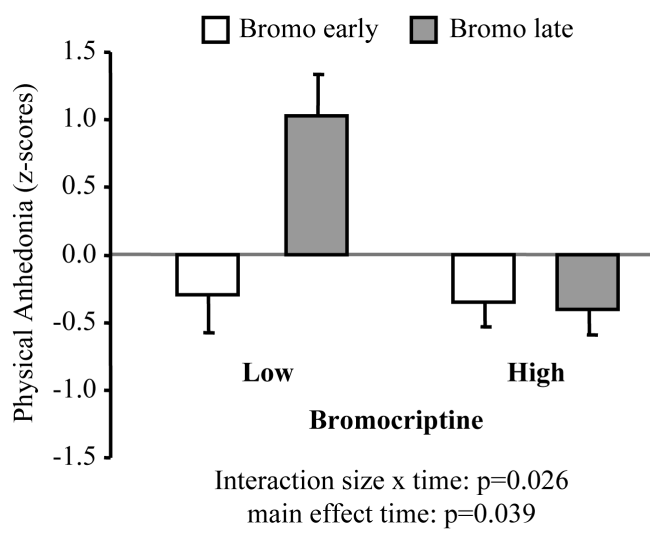

Figure 4. Physical Anhedonia according to time and size of responses to bromocriptine.

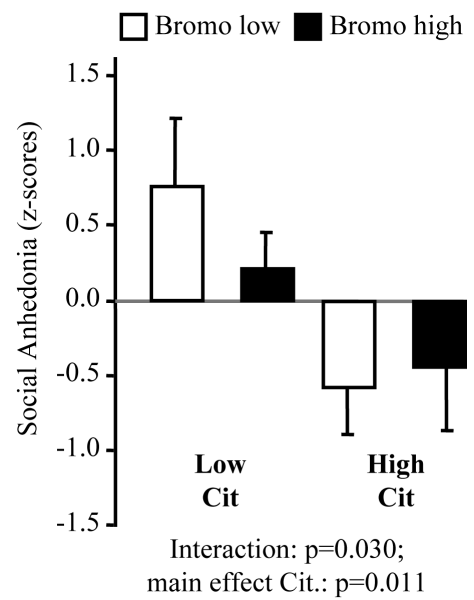

Figure 5. Social Anhedonia as related to size of responses to citalopram and bromocriptine. 


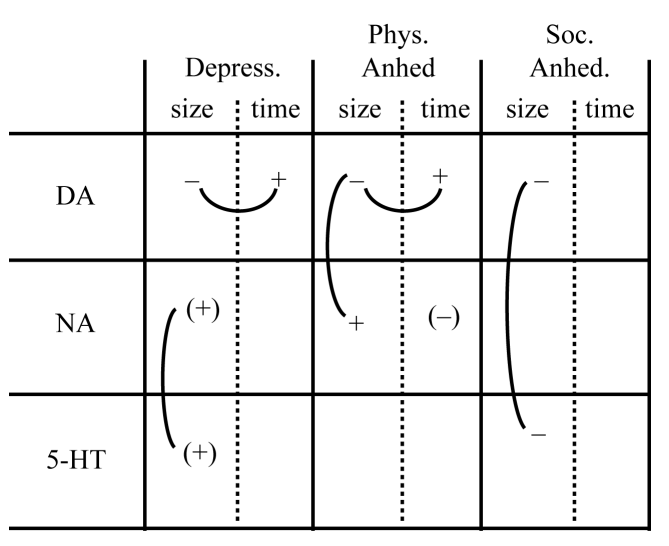

Figure 6. Summary of results for patterns of sig-
nificant transmitter response characterizing De-
pression, Physical and Social Anhedonia (DA =
dopaminergic drug (bromocriptine), NA = nora-
drenergic drug (reboxetine), 5-HT = serotonergic
drug (citalopram), + = high/late; $-=$ low/early re-
sponse; $(+)(-)=$ tendencies; curved lines = inter-
actions).

High scorers on all three scales show low DA responses, but while Physical Anhedonia shares low and late DA responses with Global Depression, it is additionally characterized by the combination of low DA with high rather early occurring NA response, while in Social Anhedonia low DA response is associated with low 5-HT responses.

\section{Discussion}

Some limitations of the study have to be discussed as a prerequisite: The usefulness of challenge tests for investigating psychopathological traits may be questioned for two reasons: 1 ) hormone responses may not only represent transmitter function but also the sensitivity or disturbance of the hypothalamo-pituitary-adrenal (HPA) axis responsible for cortisol release or of the pituitary prolactin producing cells suppressed by the tuberoinfundibular dopaminergic system. 2) Often it can not be decided, if a hormone response is due to dysfunction of transmitter production, release, receptor sensitivity, or transmitter metabolizing enzymes. The authors are aware that without additional tests for sensitivity of the endocrinological systems, the first point can not be clarified in our study, and answers to the second point can only be inferred from studies in clinical samples based on positron emission tomography (PET) or specific additional psychopharmacological experiments or on animal research based on intracerebral biochemical analyses. Yet transmitter related challenge tests have frequently been used in patients for detecting subtypes or severity of the disease or for deciding on choice of treatment and predicting treatment response. Therefore the following discussions of our results have to be regarded as cautious interpretations, but yet as promising attempts to elucidate the biological basis of clinical symptoms by using healthy volunteers as models.

Another drawback of the study may be the selection of male young persons, whose sex and age do not represent the features of patients suffering from depression. The inclusion of females would have destroyed the design, because hormone responses partly depend on the phase of the menstrual cycle (Arato \& Bagby, 1998; O'Keane et al., 1991), which would have created unequal phases of measurement in the fourfold cross-over design. Furthermore, if results obtained in young healthy males are comparable to those obtained with the same challenge tests in an older predominantly female population of depressed patients, this would rather corroborate than obscure the relationships between transmitter related responses and depression related personality dimensions.

The results obtained for Global Depression confirm previous findings that low DA responses are characteristic of depressed patients (Pitchot et al., 1992; Hansenne et al., 2002; Dailly et al., 2004), but beyond this, the combined effect of low and late responses also emphasises the finding published by Depue et al. (1994) that the time of the prolactin response to a bromocriptine challenge test may be as essential as its size. While a low size 
of response could be due to low production of DA, the late decrease of prolactin could also be due to pharmacokinetic factors in the periphery, like absorption and metabolism, but late or early responding to noradrenergic or serotonergic stimulation did not match the early versus late dopaminergic responses in our sample, so that kinetic causes in the periphery are unlikely. Since a higher density of DA receptors is found in the striatum of depressed patients (Shah et al., 1997) indicating compensatory upregulation of DA receptors due to low DA production, it may be conceived that it takes longer for the DA receptor agonist bromocriptine to obtain full receptor occupancy. It has been shown by PET studies that clinical effects or any type of response to dopaminergic stimulation depend on receptor occupancy which again depends on availability of the transmitter (e.g. Nyberg et al., 1995), so that it takes longer to reach the critical level of occupancy.

The combined high NA + high 5-HT response in depressive participants was only marginal. It may point to a common hyper-responsiveness of the HPA axis, since cortisol responses to the two transmitter related substances citalopram and reboxetin were significantly correlated $(r=0.378, p<0.05)$ This could point to hypersensitive receptors of the corticotropin releasing factor (CRF) typical for depression (Reul \& Holsboer, 2002), but it may also demonstrate the close functional association of the two transmitters on the brain level (Hetzel et al., 2004; Mongeau et al., 1997). Furthermore, the concept of pharmacotherapy of depression by mixed 5-HT + NA reuptake inhibitors implies that both types of postsynaptic receptors may be upregulated due to low 5-HT and NA production in depression and therefore are both liable to pronounced hormone responses.

Physical Anhedonia shares the low and late DA responses with global Depression confirming its close affinity to depression. The pronounced NA response confirms results observed in depressive patients (Charney et al., 1982) and in volunteers scoring high on a depression scale (Hennig et al., 2000). So the weak association found between Depression scores and NA response seems to be caused by the component of Physical Anhedonia and confirms the results reported by Shelton \& Tomarken (2001) who claimed that anhedonia is characterized by a relationship to the NA and DA system as opposed to stress and anxiety. In our study high NA receptor sensitivity could also explain the fast onset of cortisol responses to reboxetine.

Social Anhedonia shares low DA responses with Depression and Physical Anhedonia, which matches the molecular genetic finding that both Physical and Social Anhedonia were highest in relatives of schizophrenics who were homozygous for the val allel of the catechol-O-methyl-transeferase (COMT) gene (Docherty \& Sponheim, 2008) which results in faster degradation of dopamine due to a higher activity of the COMT enzyme. But Social Anhedonia seems to differ from both Physical Anhedonia and Depression by low 5-HT responses. While Physical Anhedonia was only characterised by catecholaminergic responses, Social Anhedonia shows an affinity to the serotonergic system. Blunted responses to 5-HT related drugs are frequently observed in psychopaths and antisocial or impulsive persons who are supposed to suffer from low production of 5-HT (e.g. Asberg et al., 1976). This would mean that an uptake inhibitor like citalopram can not lead to a large increase of 5-HT in the synaptic cleft so that the low response of socially anhedonic persons could be explained by low production of 5-HT. The combination of low DA and low 5-HT responses resembles the pattern described for withdrawal induced anhedonia (Rothman et al., 2002) or the type of anhedonia described as negative symptoms in schizophrenia with a predominance of social withdrawal (Wolf, 2006; Kuha et al., 2011; Juckel et al., 2003). It is conceived as a fairly enduring trait (Cohen et al., 2011) with probably a hereditary component (Docherty \& Sponheim, 2008). But it seemed worthwhile to investigate anhedonia also within the frame of depression, since transmitter responses induced by the challenge tests were able to discriminate the two components of anhedonia. These might represent the types of anhedonia encountered in depression versus in schizophrenia. In spite of a positive correlation between Physical and Social Anhedonia $(r=0.37, p<0.05)$, Physical Anhedonia is more closely related to global Depression $(r=0.387, p<0.05)$, whereas the correlation of Social Anhedonia with Depression is not significant. $(\mathrm{r}=0.130, p>0.10)$.

\section{Conclusion}

Although the causal mechanisms of hormone responses to neurotransmitter challenge tests performed in humans can not be directly assessed, challenge tests are proved to be suitable tools for discriminating two types of anhedonia and their relation to depression. This is the first study investigating anhedonia in a healthy sample by neurotransmitter response tests. These were able to show that on a biochemical level, Physical Anhedonia represented a core symptom of depression, but that Social Anhedonia might rather have an affinity to psychopathological syndromes characterised by the symptom of social withdrawal observed as a negative symptom in schi- 
zophrenia. Moreover, it was demonstrated that the time of hormone responses, when combined with their sizes, could serve as a useful tool for detecting types of transmitter disturbances and that it is essential to investigate interactions of time and size of responses as well as of different transmitter responses when trying to elucidate characteristic patterns of specific traits or symptoms. These aspects should be considered in future challenge studies. Furthermore, the study indicates that healthy volunteers can serve as models for investigating the neurobiological basis of psychopathological dimensions.

\section{Acknowledgements}

We are grateful to Claudia Toll, Anja Siegmund, and Claudia Lujic, PhD students who conducted and supervised the experiment and to Cornelia Meineke the technician in the laboratory of the Department of Psychology who measured the serum cortisol and prolactin levels.

The experiment was supported by the German Research Foundation (DFG, grant number: Ne 216-6/1).

\section{Conflict of Interest}

The authors declare that they have no conflict of interest, because the experiment was funded by the Department budget and the German Research Foundation.

\section{References}

Anderson, I. M., Ware, C. J., da Roza Davis, J. M., \& Cowen, P. J. (1992). Decreased 5-HT-Mediated Prolactin Release in Major Depression. The British Journal of Psychiatry, 160, 372-378, http://dx.doi.org/10.1192/bjp.160.3.372

Arato, M., \& Bagby, G. (1998). Gender Differences in m-CPP Challenge Tests in Healthy Volunteers. International Journal of Neuropsychopharmacology, 1, 121-124. http://dx.doi.org/10.1017/S1461145798001151

Asberg, M., Träskman, L., \& Thoren, P. (1976). 5-HIAA in the Cerebrospinal Fluid: A Biochemical Suicide Predictor? Archives of General Psychiatry, 33, 1193-1197. http://dx.doi.org/10.1001/archpsyc.1976.01770100055005

Boadie, W., Dunlop, M. D., \& Nemeroff, C. B. (2007). The Role of Dopamine in the Pathophysiology of Depression. Archives of General Psychiatry, 64, 327-337. http://dx.doi.org/10.1001/archpsyc.64.3.327

Bond, A. J. (2001). Neurotransmitters, Temperament and Social Functioning. European Neuropsychopharmacology, 11, 261-274. http://dx.doi.org/10.1016/S0924-977X(01)00094-3

Chapman, L. J., Chapman, J. P., \& Raulin, M. L. (1976). Scales for Physical and Social Anhedonia. Journal of Abnormal Psychology, 85, 374-382. http://dx.doi.org/10.1037/0021-843X.85.4.374

Charney, D. S., Heninger, G. R., Sternberg, D. E., Hafstad, K. M., Giddings, S., \& Landis, D. H. (1982). Adrenergic Receptor Sensitivity in Depression. Effects of Clonidine in Depressed Patients and Healthy Subjects. Archives of General Psychiatry, 39, 290-294. http://dx.doi.org/10.1001/archpsyc.1982.04290030030005

Cleare, A. J., Murray, R. M., \& O’Keane, V. (1996). Reduced Prolactin and Cortisol Responses to d-Fenfluramine in Depressed Compared to Healthy Matched Control Subjects. Neuropharmacology, 14, 349-354. http://dx.doi.org/10.1016/0893-133x(95)00144-3

Cohen, A. S., Najolia, G. M., Brown, L. A., \& Minor, K. S. (2011). The State-Trait Disjunction of Anhedonia in Schizophrenia: Potential Affective, Cognitive and Social-Based Mechanisms. Clinical Psychology Review, 31, 440-448. http://dx.doi.org/10.1016/j.cpr.2010.11.001

Coupland, N., Glue, P., \& Nutt, D. J. (1992). Challenge Tests of the Noradrenergic and GABA Ergic System in Depression and Anxiety. Molecular Aspects of Medicine, 13, 221-247. http://dx.doi.org/10.1016/0098-2997(92)90011-N

Dailly, E., Chenu, F., Renard, C. E., \& Bourin, M. (2004). Dopamine, Depression and Antidepressants. Fundamental \& Clinical Pharmacology, 18, 601-607. http://dx.doi.org/10.1111/j.1472-8206.2004.00287.x

Depue, R. A., Luciana, M., Arbisi, P., Collins, P., \& Leon, A. (1994). Dopamine and the Structure of Personality: Relation of Agonist-Induced Dopamine Activity to Positive Emotionality. Journal of Personality and Social Psychology, 67, 485-498. http://dx.doi.org/10.1037/0022-3514.67.3.485

Docherty, A. R., \& Sponheim, S. R. (2008). Anhedonia as a Phenotype for the Val158Met COMT Polymorphism in Relatives of Patients with Schizophrenia. Journal of Abnormal Psychology, 117, 88-98. http://dx.doi.org/10.1037/a0013745

Eysenck, H. J. (1967). The Biological Basis of Personality. Springfield, IL: Thomas.

Gerra, G., Zaimovic, A., Timpano, M., Zambelli, U., Delsignore, R., \& Brambilla, F. (2000). Neuroendocrine Correlates of Temperamental Traits in Humans. Psychoneuroendocrinology, 25, 479-496.

http://dx.doi.org/10.1016/S0306-4530(00)00004-4 
Gutkovich, Z., Morrissey, R. F., Espaillat, R. K., \& Dicker, R. (2011). Anhedonia and Pessimism in Hospitalized Depressed Adolescents. Depression Research and Treatment, 2011, Article ID: 795173. http://dx.doi.org/10.1155/2011/795173

Hansenne, M., Pinto, E., Pitchot, W., Reggers, J., Scantamburlo, G., Moor, M., \& Ansseau, M. (2002). Further Evidence on the Relationship between Dopamine and Novelty Seeking: A Neuroendocrine Study. Personality and Individual Differences, 33, 967-977. http://dx.doi.org/10.1016/S0191-8869(01)00205-7

Hasler, G., Drevets, W. C., Manji, H. K., \& Charney, D. S. (2004). Discovering Endophenotypes for Major Depression. Neuropsychopharmacology, 29, 1765-1781. http://dx.doi.org/10.1038/sj.npp.1300506

Hennig, J., Lange, N., Haag, A., Rohrmann, S., \& Netter, P. (2000). Reboxetine in a Neuroendocrine Challenge Paradigm: Evidence for High Cortisol Responses in Healthy Volunteers Scoring High on Subclinical Depression. International Journal of Neuropsychopharmacology, 3, 193-201. http://dx.doi.org/10.1017/S1461145700002029

Hennig, J., \& Netter, P. (2005). Neurotransmitter und Persönlichkeit [Neurotransmitters and Personality]. In J. Hennig, \& P. Netter (Eds.), Biopsychologische Grundlagen der Persönlichkeit [Biopsychological Basis of Personality] (pp. 191-290). Munich: Spektrum/Elsevier. http://dx.doi.org/10.1007/978-3-8274-3089-2_3

Hetzel, G. O., Moeller, A., Erfurth, N., Michael, M., Rothermundt, V., Arolt, S., \& Evers, S. (2004). The Impact of Selective Monoamine Reuptake Inhibitors Reboxetine and Citalopram on Visually-Evoked Event Related Potentials in Depressed Patients. Pharmacopsychiatry, 37, 200-205. http://dx.doi.org/10.1055/s-2004-827244

Insel, T. R., \& Siever, L. J. (1981). The Dopamine System Challenge in Affective Disorders: A Review of Behavbioral and Neuroendocrine Responses. Journal of Clinical Psychopharmacology, 1, 207-213. http://dx.doi.org/10.1097/00004714-198107000-00005

Juckel, G. L., Sass, L., \& Heinz, A. (2003). Anhedonia, Self-Experience in Schizophrenia, and Implications for Treatment. Pharmacopsychiatry, 36, 176-180. http://dx.doi.org/10.1055/s-2003-45127

Kuha, A., Suvisaari, J., Perälä, J., Eerola, M., Saarni, S. S., Partonen, T., Lönnqvist, J., \& Tuulio-Henriksson, A. (2011). Associations of Anhedonia and Cognition in Persons with Schizophrenia Spectrum Disorders, Their Siblings, and Controls. Journal of Nervous and Mental Disease, 199, 30-37. http://dx.doi.org/10.1097/NMD.0b013e3182043a6d

Lemke, M. R., Puhl, P., Koethe, N., \& Winkler, T. (1999). Psychomotor Retardation and Anhedonia in Depression. Acta Psychiatrica Scandinavica, 99, 252-256. http://dx.doi.org/10.1111/j.1600-0447.1999.tb07221.x

Lesch, K. P., Laux, G., Erb, A., Pfuller, H., \& Beckmann, H. (1988). Growth Hormone (GH) Responses to GH-Releasing Hormone in Depression: Correlation with GH Release Following Clonidine. Psychiatry Research, 25, 301-310. http://dx.doi.org/10.1016/0165-1781(88)90100-X

Livesley, W. J. (1998). Suggestions for a Framework for an Empirically Based Classification of Personality Disorder. Canadian Journal of Psychiatry, 43, 1-23.

Lotrich, F. E., Bies, R., Muldoon, M. F., Manuck, S. B., Smith, G. S., \& Pollock, B. G. (2005). Neuroendocrine Response to Intravenous Citalopram in Healthy Control Subjects. Pharmacokinetic Influences. Psychopharmacology, 178, $268-275$. http://dx.doi.org/10.1007/s00213-004-2006-4

Mattos, P. V., Franco, A., Noel, F., Segenreich, D., \& Gonçalves, J. C. (2006). Usefulness of Serotoninergic Challenge with Oral Citalopram. Revista Brasileira di Psiquiatrica, 28, 203-205. http://dx.doi.org/10.1590/S1516-44462006000300011

Mongeau, R., Blier, P. C., \& de Montigny, C. (1997). The Serotonergic and Noradrenergic Systems of the Hippocampus: Their Interactions and the Effects of Antidepressant Treatments. Brain Research Reviews, 23, 145-195. http://dx.doi.org/10.1016/S0165-0173(96)00017-3

Nakonezny, P. A. T., Carmody, J., Morris, D. W., Kurian, B. T., \& Trivedi, M. H. (2010). Psychometric Evaluation of the Snaith-Hamilton Pleasure Scale in Adult Outpatients with Major Depressive Disorder. International Clinical Psychopharmacology, 25, 328-333. http://dx.doi.org/10.1097/YIC.0b013e32833eb5ee

Netter, P. (2006). Dopamine Challenge Tests as an Indicator of Psychological Traits. Human Psychopharmacology Clinical and Experimental, 21, 91-99. http://dx.doi.org/10.1002/hup.754

Netter, P., Reuter, M., \& Hennig, J. (2004). Time of Onset of Hormone Responses to Challenge Tests, a Better Marker for Personality than Size of Responses? Journal of Physiology, 18, 241.

Nyberg, S., Nordström, A. L., Halldin, C., \& Farde, L. (1995). Positron Emission Tomography Studies on D2 Dopamine Receptor Occupancy and Plasma Antipsychotic Drug Levels in Man. International Clinical Psychopharmacology, 10, 81-85.

O’Keane, V., O’Hanlon, M., Webb, M., \& Dinan, T. (1991). D-Fenfluramine/Prolactin Response throughout the Menstrual Cycle: Evidence for an Estrogen Induced Alteration. Clinical Endocrinology, 34, 289-292. http://dx.doi.org/10.1111/j.1365-2265.1991.tb03768.x

Papp, M., Klimek, V., \& Willner, P. (1994). Parallel Changes in Dopamine D-sub-2 Receptor Binding in Limbic Forebrain Associated with Chronic Mild Stress-Induced Anhedonia and Its Reversal by Imipramine. Psychopharmacology, 115, 
441-446. http://dx.doi.org/10.1007/BF02245566

Pitchot, W., Hansenne, M., Gonzalez Moreno, A., \& Ansseau, M. (1992). Suicidal Behavior and Growth Hormone Response to Apomorphine Test. Biological Psychiatry, 31, 1213-1219. http://dx.doi.org/10.1016/0006-3223(92)90340-6

Power, A. C., \& Cowen, P. J. (1992). Neuroendocrine Challenge Tests: Assessment of 5-HT Function in Anxiety and Depression. Molecular Aspects of Medicine, 13, 205-220. http://dx.doi.org/10.1016/0098-2997(92)90010-W

Pukrop, R., Sass, H., \& Steinmeyer, E. M. (2000). Circumplex Models of the Similarity Relationships between Higher Order Factors of Personality and Personality Disorders. Comprehensive Psychiatry, 41, 438-445. http://dx.doi.org/10.1053/comp.2000.16558

Reul, J. M., \& Holsboer, F. (2002). Corticotropin-Releasing Factor Receptors 1 and 2 in Anxiety and Depression. Current Opinion in Pharmacology, 2, 23-33. http://dx.doi.org/10.1016/S1471-4892(01)00117-5

Riederer, P., \& Birkmayer, W. (1980). A New Concept: Brain Area Specific Imbalance of Neurotransmitters in Depression Syndrome-Human Brain Studies. In P. Riederer, \& W. Birkmeayer (Eds.), Enzymes and Neurotransmitters in Mental Disease (pp. 261-278). New York: Wiley.

Rothman, R. B., Blough, B. E., \& Baumann, M. H. (2002). Appetite Suppressants as Agonist Substitution Therapies for Stimulant Dependence. In S. F. Ali (Ed.), Cellular and Molecular Mechanisms of Drugs of Abuse. II: Cocaine, Substituted Amphetamines, GHB, and Opiates (pp. 109-126). New York: New York Academy of Sciences.

Ruegg, R. G., Gilmore, J., Ekstrom, R. D., Corrigan, M., Knight, B., Tancer, M., Leatherman, M. E., Carson, S. W., \& Golden, R. N. (1997). Clomipramine Challenge Responses Covary with Tridimensional Personality Questionnaire Scores in Healthy Subjects. Biological Psychiatry, 42, 1123-1129. http://dx.doi.org/10.1016/S0006-3223(97)00009-7

Schüle, C., Baghai, T., Schmidbauer, S., Bidlingmaier, M., Strasburger, C. J., \& Laakmann, G. (2004). Reboxetine Acutely Stimulates Cortisol, ACTH, Growth Hormone and Prolactin Secretion in Healthy Male Subjects. Psychoneuroendocrinology, 29, 185-2004. http://dx.doi.org/10.1016/S0306-4530(03)00022-2

Shah, P. J., Ogilvie, A. D., Goodwin, G. M., \& Ebmeier, K. O. (1997). Clinical and Psychometric Correlates of Dopamine D-2 Binding in Depression. Psychological Medicine, 27, 1247-1256. http://dx.doi.org/10.1017/S0033291797005382

Shelton, R. A., \& Tomarken, J. (2001). Can Recovery from Depression Be Achieved? Psychiatric Services, 52, $1469-1478$. http://dx.doi.org/10.1176/appi.ps.52.11.1469

Snaith, P. (1993). Anhedonia: A Neglected Symptom of Psychopathology. Psychological Medicine, 23, 957-966. http://dx.doi.org/10.1017/S0033291700026428

Stein, D. J. (2008). Depression, Anhedonia, and Psychomotor Symptoms: The Role of Dopaminergic Neurocircuitry. CNS Spectrums, 13, 561-565.

Van de Kar, L. D. (1998). Methods in Neuroendocrinology. Boca Raton, FL: CRC Press.

Von Zerssen, D., \& Koeller, D. M. (1976). Depressivitätsskala: Manual [Depression Scale: Manual]. Weinheim: Beltz Test Gesellschaft.

Widiger, T. A. (2011). Personality and Psychopathology. World Psychiatry, 10, 103-106. http://dx.doi.org/10.1002/j.2051-5545.2011.tb00024.x

Willner, P. (1995). Pharmacology of Anhedonia. European Neuropsychopharmacology, 5, 214. http://dx.doi.org/10.1016/0924-977X(95)90243-7

Willner, P. (2005). Chronic Mild Stress Revisited: Consistency and Behavioural Neurobiological Concordance in the Effects of CMS. Neuropsychobiology, 52, 90-110. http://dx.doi.org/10.1159/000087097

Wolf, D. H. (2006). Anhedonia in Schizophrenia. Current Psychiatry Reports, 8, 322-328. http://dx.doi.org/10.1007/s11920-006-0069-0

Yatham, L. N., \& Steiner, M. (1993). Neuroendocrine Probes of Serotonergic Function: A Critical Review. Life Sciences, 53, 447-463. http://dx.doi.org/10.1016/0024-3205(93)90696-Z 